\title{
TERRITÓRIOS RELIGIOSOS E SUAS INTERFACES TEMÁTICAS
}

\author{
Valdery Ferreira Zotelli \\ Mestrando em Desenvolvimento Local -PPGDL-UCDB-MS \\ valderyzotelli@gmail.com \\ Michael hideky Kubota \\ Mestrando em Desenvolvimento Local -PPGDL-UCDB-MS \\ arqmhk@gmail.com
}

Arlinda Cantero Dorsa

Doutora em Língua Portuguesa e docente do Programa de Pós-Graduação em Desenvolvimento Local

acdorsa@ucdb.br

\section{RESUMO}

Este artigo focaliza as interfaces temáticas que se relacionam ao descritor "territórios religiosos", a partir do mapeamento de dissertações referentes aos anos de 2013-2020, encontradas na plataforma do banco de dissertações e teses da Capes. Este tema traz relevância em razão dos diferentes enfoques simbólicos culturais e principalmente por propiciar um panorama das produções existentes na pósgraduação stricto sensu em nosso país. Enfatiza-se que o presente trabalho busca a elaboração de uma síntese integrativa do estado de conhecimento sobre a referida temática, objetivando a visibilidade e divulgação cientifica, facilitando assim o acesso, a pesquisa e o aprofundamento desta área de conhecimento, válida para todos os membros os membros da comunidade acadêmica de diferentes áreas de conhecimento, sejam eles alunos de graduação, pós-graduação e docentes pesquisadores e orientadores. Integra-se esta pesquisa em uma discussão mais ampla, desenvolvida pelo "Grupo de Pesquisa em Patrimônio Cultural, Direitos e Diversidade", formado por professorespesquisadores da Graduação e do Mestrado e Doutorado em Desenvolvimento Local, pósgraduandos/orientandos, acadêmicos em iniciação científica, com uma visão interdisciplinar. Os resultados foram obtidos a partir do refinamento dos resultados: Descritor, ano, tipo, grande área de conhecimento, área de avaliação, área de concentração, Instituições e Programas. A partir de uma análise aprofundada dos trabalhos selecionados concluiu-se que se trata de um tema interdisciplinar e multidisciplinar, com abordagens em diversas áreas do conhecimento e diferentemente dos outros processos de ocupação do espaço com óticas econômicas, a visão religiosa não apresenta explicações ligadas ao mundo material, mas sim sagrado e as suas várias manifestações.

Palavras-chave: Territórios; Territorialidades religiosas; Estado da arte. 


\section{ABSTRACT}

\section{RELIGIOUS TERRITORIES AND THEIR THEMATIC INTERFACES}

This article focuses on the thematic interfaces related to the descriptor "religious territories", based on the mapping of dissertations from 2013-2020, found on the platform of the Capes dissertation and thesis database. This theme is relevant because of the different symbolic cultural approaches and mainly because it provides an overview of existing productions in the post-graduation stricto sensu in our country. It is emphasized that the present work seeks to elaborate an integrative synthesis of the state of knowledge on this theme, aiming at the visibility and scientific disclosure, thus facilitating the access, the research, and the deepening of this area of knowledge, valid for all the members of the academic community from different areas of knowledge, whether they are undergraduate or graduate students, and professors, researchers, and advisors. This research is part of a wider discussion, developed by the "Research Group on Cultural Heritage, Rights and Diversity", formed by teacherresearchers from the Undergraduate and the Master's and Doctorate in Local Development, postgraduate students/guidancers, academics in scientific initiation, with an interdisciplinary vision. The results were obtained from the refinement of the results: Descriptor, year, type, major area of knowledge, area of evaluation, area of concentration, Institutions and Programs. From an in-depth analysis of the selected works it was concluded that it is an interdisciplinary and multidisciplinary theme, with approaches in various areas of knowledge and differently from other processes of occupation of space with economic optics, the religious view does not present explanations linked to the material world, but to the sacred and its various manifestations.

Keywords: Territories; Religious Territorialities; State of art.art. 


\section{CONSIDERAÇÕES INICIAIS}

É relevante afirmar que na formação territorial dos territórios religiosos, os processos de domínio e ocupação são responsáveis pela modificação do espaço e são fundamentalmente simbólicos no contexto cultural, político e econômico, tendo como principal agente da configuração territorial a religião.

A importância científica desta temática relaciona-se à discussão nos meios acadêmicos acerca das interfaces temáticas que se relacionam aos descritores "territórios religiosos" tema este de relevante importância por envolver diferentes enfoques simbólicos culturais e por entendermos ser relevantes para a comunidade científica em razão de poder propiciar um panorama do que se produz em nível de pós-graduação stricto sensu em nosso país, relacionados a esta temática.

Objetiva, portanto, esta pesquisa analisar as interfaces temáticas relacionadas ao descritor "territórios religiosos", nas dissertações referentes aos anos de 2013-2020, encontradas na plataforma do banco de dissertações e teses da Capes.

Enfatiza-se, neste contexto, o papel fundamental da plataforma CAPES por desempenhar frente à comunidade científica, a visibilidade para o intercâmbio acadêmico e enriquecimento de conhecimentos das diversas áreas do conhecimento e gerando assim, a divulgação científica para a sociedade em geral.

Com relação à metodologia utilizada, a pesquisa pautou-se em duas fases: a primeira destinou-se à revisão bibliográfica relativa às questões e às temáticas concernentes ao tema, com a apropriação e amadurecimento de referenciais teóricos e uma segunda fase, voltada à elaboração do mapeamento com abordagem quantitativa e análise das interfaces temáticas.

Para a consecução deste objetivo pretende: conceituar território religioso e estado da arte, elaborar um mapeamento dos trabalhos e enfim apresentar uma abordagem quantitativa e análise das interfaces temáticas encontradas nas referidas dissertações. 


\section{PRINCÍPIOS CONCEITUAIS: TERRITÓRIOS E TERRITORIALIDADES RELIGIOSAS}

Para a compreensão do conceito simbólico-cultural de território e territorialidade pela perspectiva da religião e da religiosidade, é necessária a adoção de parâmetros conceituais no âmbito da geografia.

Raffestin (1993) destaca que o território se constitui a partir do espaço, construído através da força e mobilização dos atores locais de desenvolvimento. A transformação de um espaço em território passa pela territorialização, processo em que os atores locais se apropriam do espaço e o transformam, seja na dimensão física ou simbólica.

Na mesma linha de pensamento, Santos (1997) aponta que a territorialidade é o sentimento de pertença, sendo despertado através da participação coletiva na transformação do espaço. A julgar que a noção de território está associada com o sentimento de propriedade, os autores se empenham em um projeto de desenvolvimento coletivo de construção do território.

O território então nesta perspectiva conceitual pode ser visto como uma porção do espaço apropriado/utilizado por um grupo humano na utilização de práticas de garantia utilizadas para a sobrevivência neste espaço. Nas palavras de Haesbaert (2004), o território pode ser visto por alguns em uma perspectiva política e mesmo cultural, contudo em "uma perspectiva geográfica, vê a territorialização como o processo de domínio (políticoeconômico) e/ou apropriação (simbólico-cultural) do espaço pelos grupos humanos".(HAESBAERTH, 2004, p. 16).

Na concepção de território religioso, Rosendahl (2005) define-o como um território demarcado, controlado em seus acessos e ações por um profissional religioso; complementa esta afirmação Weber (1991), ao definir a presença de três agentes neste espaço definido: a) o profeta religioso, dotado de carisma; b) o sacerdote produtor do sagrado, responsável pela difusão da doutrina e da ideologia da instituição religiosa; c) o leigo, consumidor do sagrado.

Outro aspecto importante é reconhecer que para a formação do território religioso, o aspecto simbólico e cultural é mais representativo e as territorialidades são relacionadas ao sagrado e sobre elas, Rosendahl (2005) afirma que se trata: “[...] de um conjunto de práticas desenvolvidas por instituições ou grupos no sentido de controlar um dado território, onde o 
efeito do poder do sagrado reflete uma identidade de fé e um sentimento de propriedade mútuo". (ROSENDAHL, 2005, p.204).

A autora ainda afirma que a visão territorial é um reflexo de uma identidade cultural no qual o sentimento de pertencimento é um sentimento comum e mútuo entre seus integrantes. Isto implica incluir o modo como os espaços e gestão do espaço são distribuídos e inscritos em sua significação na paisagem, com alcance visto de forma coletiva.

Assim, é necessário ressaltar que a territorialização do espaço religioso ocorre de maneira oposta às demais atividades inerentes à vida humana. O território religioso é um espaço de manifestação do sagrado, carregado de uma simbologia própria que não se limita ao mundo tangível, explicável apenas na fé do homem religioso que busca esses espaços como forma de ligação ou proximidade com o sagrado.

Os espaços religiosos são construídos de forma coletiva por uma comunidade através de suas vivências e limitado a seu arcabouço cultural, podendo estar ligado ao território natural, ou contido em objetos e pessoas. Assim sendo, é preciso considerar que um mesmo território pode despertar diferentes sensações em grupos ou comunidades distintas, resultando em conflitos religiosos que marcam a trajetória da humanidade.

Pode-se afirmar que os territórios religiosos são múltiplos e plurais e podem ser reconhecidos nos estudos de territorialidade religiosa, a partir de três comportamentos diferenciados: coexistência pacífica, instabilidade e competição e intolerância e exclusão.

\section{DO ESTADO DA ARTE}

Ao possibilitar as percepções discursivas, que em um primeiro momento se apresenta como descontínuos ou contraditórios, Ferreira (2002) afirma que o interesse dos pesquisadores que se voltam para a realização de mapeamentos é a sensação do não conhecimento acerca da totalidade de estudos e pesquisas e seu crescimento qualitativo e quantitativo. Alguns questionamentos emergem e voltam, segundo a autora, a perceber de que formas e em que condições têm sido produzidas certas dissertações de mestrado, teses de doutorado, publicações em periódicos e comunicações em anais de congressos e de seminários.

Amplia a discussão a referida autora, ao afirmar que: 
Também são reconhecidas por realizarem uma metodologia de caráter inventariante e descritivo da produção acadêmica e científica sobre o tema que busca investigar, à luz de categorias e facetas que se caracterizam enquanto tais em cada trabalho e no conjunto deles, sob os quais o fenômeno passa a ser analisado. (FERREIRA, 2002, p.252)

Neste artigo, o que desafia os autores, é a possibilidade de construção de uma contextualização sobre as temáticas abordadas, assim como análise das possibilidades presentes para a concepção de um novo referencial teórico.

Há que se considerarem dois eixos estruturantes dando sustentação aos estudos do tipo estado da arte ou conhecimento, segundo Slongo (2004) que são: o aspecto quantitativo, ou seja, o significativo crescimento numérico das produções e/ou a variação dessas produções num lapso específico de tempo sem que se considere, nessa vertente de atuação, a qualidade dessas produções e também aponta um importante aspecto qualitativo - a diversidade de enfoques.

De caráter inventariante, o estado da arte propicia uma visão crítica do contexto evolutivo de um assunto ou tema, apontando para novos caminhos a serem trilhados pelos pesquisadores a fim de contribuir para a solução mais efetiva dos problemas sociais. Para mais, presta-se a conferir visibilidade aos avanços científicos, em atenção à função social de disseminação do conhecimento e da informação. (SHIOTA;DORSA, 2019, p. 35)

O desafio então para os pesquisadores consiste a partir do estado da arte de dar conta de determinado saber como também de buscar aquilo que ainda poderá ser feito.

\section{O MAPEAMENTO REALIZADO}

O trabalho inicial consistiu na pesquisa bibliográfica realizada no Banco de Teses e dissertações da Capes entre os anos de 1990-2020, a partir de abordagem quantitativa.

Como segundo passo, foi submetida como descritor a palavra "territórios religiosos", conforme mostra a figura 1, obtendo-se como resultado 12.816 teses e dissertações referente a temática, em busca ampla. 


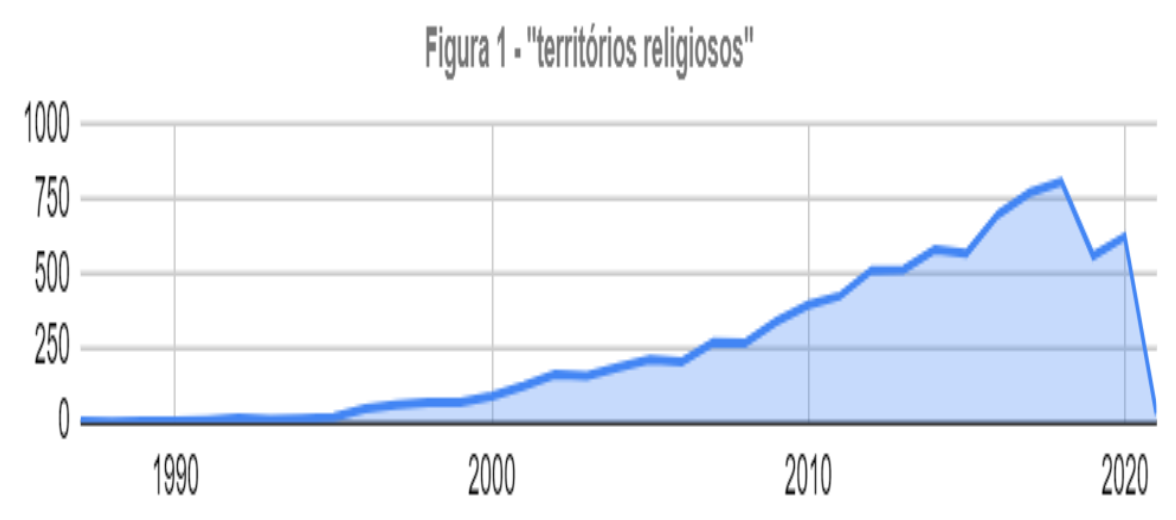

O terceiro passo consistiu no refinamento dos resultados com os seguintes filtros: "Dissertações", com o objetivo de delimitar as buscas apenas entre as produções em âmbito de mestrado, como mencionado nos objetivos deste trabalho. Como resultado foi obtido um total de 8449 dissertações que estão relacionadas com os descritores mesmo que seja em um sentido amplo.

Em seguida foi adicionado a pesquisa o filtro "Anos", selecionando apenas os trabalhos que estavam listados entre 2013-2020. Dentro disso, obtivemos os seguintes resultados:

2013 - foram encontrados 511 trabalhos, em 2014 foram 579, em 2015 foram localizados 567, em 2016 foram encontrados 698 trabalhos, em 2017 foram 771, em 2018 foram localizados 808 trabalhos, em 2019 foram encontrados 559 e em 2020623 trabalhos. Portanto,

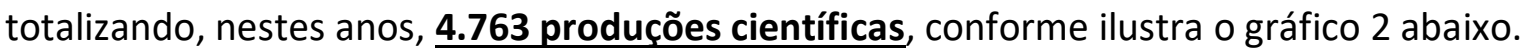

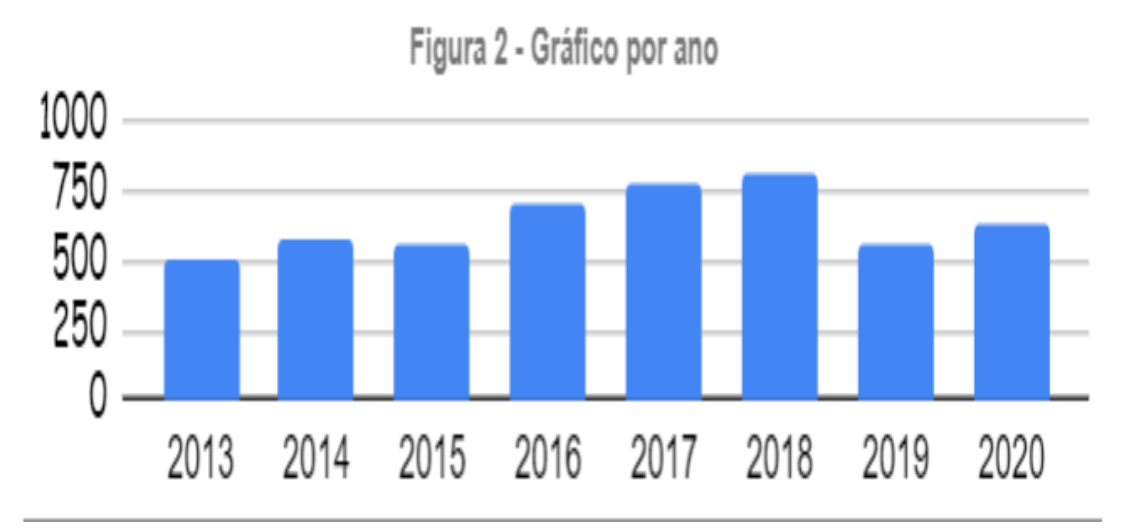


Desta maneira, o quarto passo da pesquisa foi a seleção da área de "Ciências Humanas" como Grande Área Conhecimento e como quinto passo, foram selecionadas as seguintes áreas de conhecimento listadas abaixo.

A primeira área do conhecimento analisada foi Geografia, onde por meio deste refinamento foram encontrados um total de 516 dissertações. A segunda seleção foi feita a partir da área de conhecimento História, onde foram encontrados um total de 452 dissertações referente ao tema proposto. Em sequência ainda foram selecionados trabalhos das áreas de conhecimento relacionados à Comunicação Social e Serviço social, por apresentarem os descritores em seus títulos e resumo.

O sexto passo foi o mapeamento das universidades em suas respectivas regiões, conforme gráfico 2 abaixo. Nesse filtro, chama atenção a região sudeste, onde foram localizados os principais trabalhos selecionados para este trabalho. Da mesma forma, não podemos deixar de mencionar a ausência de trabalhos referente à temática representando a região norte do país, fato que pode ser explicado pelo mapeamento ter sido elaborado após todo o critério de exclusão e seleção das dissertações importantes para o trabalho.

Conforme, aponta a figura 3, abaixo, é possível identificar como estão distribuídos os trabalhos utilizados neste artigo:

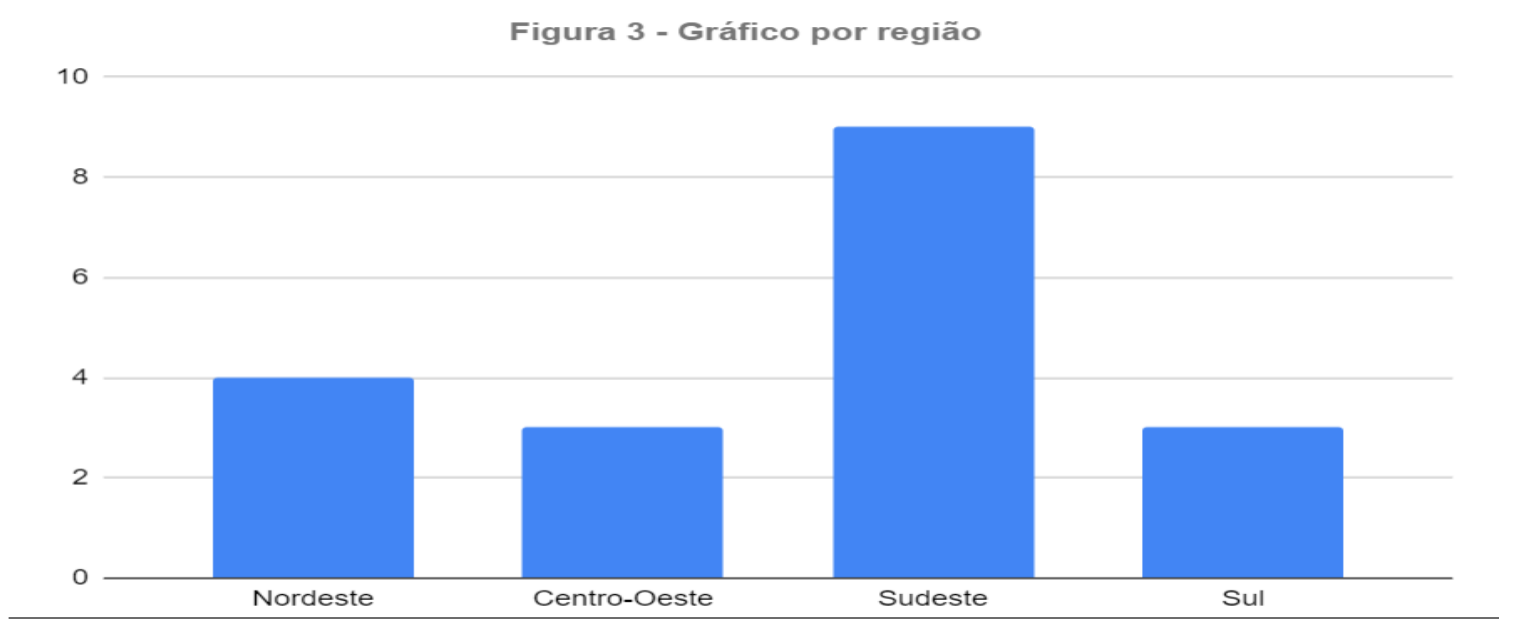

Desta maneira, a presente pesquisa científica apresentou a abordagem quantitativa das 8489 dissertações a partir do descritor "territórios religiosos", de todas as Instituições apresentadas. Para tal investigação, o filtro final foi a análise das interfaces temáticas a partir 
da seleção das dissertações por meio da presença do descritor no título, resumo ou palavraschaves, conforme quadro 1 abaixo

Como passos sequenciais, as referidas dissertações foram agrupadas a partir do programa de mestrado que representam em quadros contendo: título, autor, palavras chave, programa e Universidade.

Ao final do mapeamento e da análise das dissertações encontradas, foram selecionadas cinco (5) dissertações em Ciências da Religião. Em relação a estas dissertações foi possível analisar as diferentes interfaces temáticas:

Quadro 1: Dissertações analisadas segundo o Programa de Ciências da Religião.

\begin{tabular}{|c|c|c|c|c|}
\hline Titúlo & Autor & Palavras - Chaves & Programa & Universidade \\
\hline $\begin{array}{c}\text { Embates da Fé: conflitos religiosos entre } \\
\text { congregacionais e católicos no sertão da } \\
\text { Paraíba (1930-1940) }\end{array}$ & $\begin{array}{l}\text { Bruno Cesar } \\
\text { Cordeiro de } \\
\text { Araujo }\end{array}$ & $\begin{array}{l}\text { Estado. Igreja. Poder. } \\
\text { Movimentos de resistência. } \\
\text { Congregacionalismo. }\end{array}$ & $\begin{array}{l}\text { Ciência da } \\
\text { Religião }\end{array}$ & $\begin{array}{l}\text { Universidade } \\
\text { Católica de } \\
\text { Pernambuco }\end{array}$ \\
\hline $\begin{array}{l}\text { Religião em ambientes digitais: o discurso } \\
\text { religioso e possibilidades de diálogo na } \\
\text { perspectiva de Mikhail Bakhtin }\end{array}$ & $\begin{array}{l}\text { Rogerio Tiago } \\
\text { Miguel }\end{array}$ & $\begin{array}{c}\text { Religião. Discurso Religioso. } \\
\text { Ambientes Digitais Religiosos. } \\
\text { Dialogismo. }\end{array}$ & $\begin{array}{l}\text { Ciência da } \\
\text { Religião }\end{array}$ & $\begin{array}{l}\text { Pontifícia } \\
\text { Universidade } \\
\text { Católica de } \\
\text { Minas Gerais }\end{array}$ \\
\hline $\begin{array}{l}\text { Mapeamento e Pluralismo: a territoralidade } \\
\text { religiosa no bairro do pina em Recife }\end{array}$ & $\begin{array}{c}\text { Maria Vanessa } \\
\text { Nunes do Carmo }\end{array}$ & $\begin{array}{l}\text { Pluralismo Religioso. } \\
\text { Cartografia. Bairro do Pina }\end{array}$ & $\begin{array}{l}\text { Ciência da } \\
\text { Religião }\end{array}$ & $\begin{array}{l}\text { Universidade } \\
\text { Católica de } \\
\text { Pernambuco }\end{array}$ \\
\hline $\begin{array}{l}\text { Católicos:"Falsos" versus "verdadeiros": } \\
\text { observando relações de poder entre dois grupos } \\
\text { religiosos na cidade de Capanema-PA }\end{array}$ & $\begin{array}{l}\text { Aline Ellen dos } \\
\text { Santos Mota }\end{array}$ & $\begin{array}{l}\text { Catolicismos. Capanema. "Falsos } \\
\text { Católicos". "Verdadeiros } \\
\text { Católicos". Dissidência. Igreja } \\
\text { Católica Separa. }\end{array}$ & $\begin{array}{l}\text { Ciência da } \\
\text { Religião }\end{array}$ & $\begin{array}{l}\text { Universidade do } \\
\text { Estado do Pará }\end{array}$ \\
\hline $\begin{array}{c}\text { A territorialidade da Igueja Católica em } \\
\text { Colatina-ES: um olhar a partir de Zeny } \\
\text { Rosendahl }\end{array}$ & $\begin{array}{c}\text { Daniel Louzada } \\
\text { Casteluber }\end{array}$ & $\begin{array}{c}\text { Espaço. Sagrado. } \\
\text { Territorialidade. Religião. Igreja } \\
\text { Católica }\end{array}$ & $\begin{array}{l}\text { Ciência da } \\
\text { Religião }\end{array}$ & $\begin{array}{l}\text { Faculdade de } \\
\text { Vitória }\end{array}$ \\
\hline
\end{tabular}

Na dissertação de Casteluber (2014), foi feito um estudo procurando dar uma visão sobre o processo de construção do território relacionado à questão do poder e dominação religiosa da cidade de Colatina-ES, singularizando a contribuição das Instituições religiosas no processo de construção do espaço geográfico da cidade.

Já, Mota (2016), realizou um estudo onde foram observadas as relações divergentes entre dois grupos religiosos católicos. Para isso, foram observados como exemplo das classificações impostas pela comunidade aos recém-chegados e aos que por ela foram "convertidos" como "falsos católicos", visto que os primeiros se intitulam como "verdadeiros católicos". 
Carmo (2017), em seu trabalho, buscou a delimitação da área baseando-se num espaço amostral de 55 núcleos religiosos, em que os cenários atuais do bairro do Pina indicam uma perspectiva de transformações do ambiente por meio das atividades religiosas, mostrando que essa diversidade é convertida num processo de demarcação de territórios, provocando uma reconstrução do espaço.

Já a dissertação de Miguel (2017), destaca que as religiões se deparam com um novo cenário de modelo comunicacional, na qual devem admitir que não podem permanecer no modelo tradicional. Com isso, as tecnologias digitais podem ser aliadas às práticas religiosas onde a prática religiosa adquire novos significados ampliando o diálogo entre os fiéis.

Por fim, o trabalho de Araujo (2020), objetivou demonstrar os conflitos entre a igreja católica em relação aos protestantes congregacionais entre as décadas de 1930 e 1940. Vários documentos foram examinados para explicar que tipo de ameaça esse movimento ofereceria no sentido de reconstruir a história dos conflitos religiosos e das comunidades envolvidas no Sertão da Paraíba.

Em relação ao Programa de Geografia, foram levantadas 8 dissertações, que possibilitaram a verificação dos seguintes pontos:

Quadro 2: Dissertações analisadas segundo o Programa de Geografia. 


\begin{tabular}{|c|c|c|c|c|}
\hline Titúlo & Autor & Palavras - Chaves & Programa & Universidade \\
\hline $\begin{array}{c}\text { Estratégias de difusão espacial do } \\
\text { Protestantismo no Estado do Rio de Janeiro: } \\
\text { o caso da Igreja Projeto Vida Nova }\end{array}$ & $\begin{array}{l}\text { Roberta Crista } \\
\text { Martins Dias }\end{array}$ & $\begin{array}{c}\text { Difusão espacial da fé. } \\
\text { Território religioso. Espaços } \\
\text { públicos. }\end{array}$ & Geografia & $\begin{array}{l}\text { Universidade do } \\
\text { Estado do Rio de } \\
\text { Janeiro }\end{array}$ \\
\hline $\begin{array}{l}\text { A romaria de Santa Luzia: contribuições da } \\
\text { fé para a construção de uma identidade } \\
\text { territorial na comunidade de Santa Luzia - } \\
\text { município de Porangatu/GO }\end{array}$ & $\begin{array}{l}\text { Marcos Roberto } \\
\text { Pereira Moura }\end{array}$ & $\begin{array}{c}\text { Território religioso. } \\
\text { Catolicismo. Romaria. } \\
\text { Identidade. Comunidade de } \\
\text { Santa Luzia }\end{array}$ & Geografia & $\begin{array}{c}\text { Universidade } \\
\text { Federal de Goiás }\end{array}$ \\
\hline $\begin{array}{c}\text { Difusão espacial da religião: Igreja } \\
\text { Metodista em São Francisco, Niterói, a } \\
\text { prática religiosa em células }\end{array}$ & $\begin{array}{l}\text { Rosana Jardim } \\
\text { Madureira }\end{array}$ & $\begin{array}{l}\text { Difusão Espacial. Território } \\
\text { Religioso. Geografia da } \\
\text { Religião }\end{array}$ & Geografia & $\begin{array}{l}\text { Universidade do } \\
\text { Estado do Rio de } \\
\text { Janeiro }\end{array}$ \\
\hline $\begin{array}{c}\text { De lugar segregado ao lugar espiritual da } \\
\text { Teologia da Libertação: Diocese de Nova } \\
\text { Iguaçu de } 1970 \text { a } 1990\end{array}$ & $\begin{array}{l}\text { Suellen Santigo } \\
\text { dos Reis }\end{array}$ & $\begin{array}{l}\text { Diocese de Nova Iguaçu. } \\
\text { Baixada Fluminense. Dom } \\
\text { Adriano Hypólito. Teologia } \\
\text { da Libertação. Comunidade }\end{array}$ & Geografia & $\begin{array}{l}\text { Universidade do } \\
\text { Estado do Rio de } \\
\text { Janeiro }\end{array}$ \\
\hline $\begin{array}{c}\text { Território da Religiosidade: fé, mobilidade e } \\
\text { símbolos na construção do espaço sagrado } \\
\text { da romaria do senhor do bonfim em } \\
\text { Araguacema-TO }\end{array}$ & $\begin{array}{c}\text { Jose Rodrigues } \\
\text { de Carvalho }\end{array}$ & $\begin{array}{c}\text { Territórios religiosos. } \\
\text { Bandeiras Verdes. } \\
\text { Territorialidades simbólicas. } \\
\text { Simbolismo. Trajetórias. }\end{array}$ & Geografia & $\begin{array}{c}\text { Universidade } \\
\text { Federal de Goiás }\end{array}$ \\
\hline $\begin{array}{c}\text { Campo da Fé: território e territorialidades } \\
\text { dos peregrinos sergipanos na Jornada } \\
\text { Mundial da Juventude: Rio de Janeiro/2013 }\end{array}$ & $\begin{array}{l}\text { Eliete Furtado } \\
\text { Cecilio E. Silva }\end{array}$ & $\begin{array}{c}\text { Territorialidades. Peregrinos. } \\
\text { Jornada Mundial da } \\
\text { Juventude }\end{array}$ & Geografia & $\begin{array}{c}\text { Fundação } \\
\text { Universidade } \\
\text { Federal de Sergipe }\end{array}$ \\
\hline $\begin{array}{c}\text { Campina Grande - PB, A "Capital da Fé”: } \\
\text { entre Territórios e (re)Construções } \\
\text { Identitárias }\end{array}$ & $\begin{array}{l}\text { Debora Vanessa } \\
\text { Regis Ferreira } \\
\text { Sampaio }\end{array}$ & $\begin{array}{l}\text { Geografia Cultural. } \\
\text { Identidade. Eventos } \\
\text { Religiosos. Território. } \\
\text { Territorialidade. }\end{array}$ & Geografia & $\begin{array}{l}\text { Universidade } \\
\text { Estadual do Oeste } \\
\text { do Paraná }\end{array}$ \\
\hline $\begin{array}{c}\text { "Daí pra cá é meu": territorialidades no } \\
\text { contexto da festa do divino pai eterno em } \\
\text { Trindade-GO }\end{array}$ & $\begin{array}{l}\text { Lorrana Laila } \\
\text { Silva de Almeida }\end{array}$ & $\begin{array}{l}\text { Festa religiosa. Território. } \\
\text { Peregrinação. Religião. }\end{array}$ & Geografia & $\begin{array}{l}\text { Uberlândia-MG } \\
\text { Universidade } \\
\text { Federal de } \\
\text { Uberlândia - MG }\end{array}$ \\
\hline
\end{tabular}

Na Dissertação de Reis (2013), a pesquisa consistiu em esclarecer sobre as ações no processo histórico e geográfico da Diocese de Nova Iguaçu, localizada na Baixada Fluminense, buscando entender o papel que a igreja teve para a sociedade iguaçuana nas décadas de 1970 a 1990 e de como a relação da dimensão política e religiosa interagem e intervém na sociedade.

No que diz a respeito à dissertação de Carvalho (2014), a pesquisa procurou conhecer o mundo religioso de forma peculiar, através de experiências de fé, romarias, dos símbolos, tradições e da influência dos valores simbólicos que tornam os santuários significativos para o ser religioso e para a geografia cultural.

A dissertação "Difusão espacial da religião: Igreja Metodista em São Francisco, Niterói, a prática religiosa em células, (2014), segundo a autora Rosana Jardim Madureira mostra a dimensão da política religiosa da igreja Metodista e a sua organização territorial, onde a gestão religiosa incentiva à organização da Igreja em Célula. 
No que tange à dissertação de Moura (2015), foi possível identificar que a festa religiosa é considerada além de um ato de devoção dos peregrinos, um patrimônio da comunidade local, o que contribuiu para a formação de uma identidade territorial, tradições e ritos vinculados à festa, demarcando a configuração dos territórios religiosos da igreja católica no município de Porangatu.

Segundo Silva (2016), em sua dissertação, foi feito um estudo durante a Jornada Mundial da Juventude (JMJ, 2013), buscando analisar os territórios e as territorialidades construídas durante o evento. Foi observado a importância para os peregrinos sergipanos e como se mobilizaram, congregaram e construíram as redes de amizades, possibilitando uma organização missionária em nível local e o encontro de comunidades de várias partes do Brasil e do mundo.

Já para Roberta Cristina Martins Dias ( 2016 ) em “Estratégias de difusão espacial do Protestantismo no Estado do Rio de Janeiro: o caso da Igreja Projeto Vida", foi feita uma pesquisa analisando as estratégias de difusão espacial do protestantismo e o crescimento de grupos evangélicos através do exemplo empírico da igreja projeto vida nova no Estado do Rio de Janeiro.

Na dissertação de Sampaio (2018), a pesquisa buscou verificar os processos que influenciaram a (re)construção identitária em Campina Grande-PB, buscando informação e compreensão sobre fenômenos religiosos, e verificou-se a formação de territórios e territorialidades religiosas e os processos que influenciaram esta (re)construção identitária nesta cidade.

Por fim, na dissertação de Almeida (2020), o objetivo do trabalho foi analisar como se configura a territorialidade no contexto da Festa do Divino Pai Eterno em Trindade-GO. Foi observado no contexto da peregrinação, a atuação principalmente de comerciantes no trajeto da romaria e o domínio da igreja e do poder público como os detentores de controle e disputas territoriais.

Já em relação ao Programa de História, foram levantadas 3 dissertações, que possibilitaram a verificação dos seguintes pontos: 
Quadro 3: Dissertações analisadas segundo o Programa de História.

\begin{tabular}{|c|c|c|c|c|}
\hline Titúlo & Autor & Palavras - Chaves & Programa & Universidade \\
\hline $\begin{array}{l}\text { A Festa de São Benedito: estudo sobre a } \\
\text { invenção de uma tradição cuiabana }\end{array}$ & $\begin{array}{l}\text { Sibele Correa } \\
\text { Perassolo Silva }\end{array}$ & $\begin{array}{c}\text { História e Historiografia. } \\
\text { Religião. Cuiabá-MT. } \\
\text { Festividade religiosa. } \\
\text { Cultura Cuiabana. }\end{array}$ & História & $\begin{array}{l}\text { Universidade } \\
\text { Federal de Mato } \\
\text { Grosso }\end{array}$ \\
\hline $\begin{array}{l}\text { Levantes Religiosos e combate ao diabo: } \\
\text { concepções e práticas sociais no norte da } \\
\text { África entre os séculos IV e V }\end{array}$ & $\begin{array}{c}\text { Juliana Marques } \\
\text { Morais }\end{array}$ & $\begin{array}{l}\text { Norte da África. } \\
\text { Perseguição. Conflitos } \\
\text { religiosos. Práticas sociais. } \\
\text { Antiguidade Tardia. }\end{array}$ & História & $\begin{array}{l}\text { Universidade } \\
\text { Estadual de } \\
\text { Londrina }\end{array}$ \\
\hline $\begin{array}{l}\text { As relações entre os confrontos religiosos } \\
\text { e os lugares cristões das cidades do norte } \\
\text { da África durante a antiguidade tardia }\end{array}$ & $\begin{array}{l}\text { Giovan do } \\
\text { Nascimento }\end{array}$ & $\begin{array}{l}\text { Conflito Religioso. Cultura } \\
\text { Material. Norte da África. } \\
\text { Antiguidade Tardia }\end{array}$ & História & $\begin{array}{l}\text { Universidade } \\
\text { Estadual de } \\
\text { Londrina }\end{array}$ \\
\hline
\end{tabular}

Na dissertação de Silva (2014), a origem da festa de São Benedito ocorreu junto com a fundação da vila, no século XVIII, referência na construção da tradição e sendo visto como a maior festa religiosa de devoção ao santo negro. Ela é realizada no mês de julho, contribuindo para a historiografia da igreja Católica da Capital e refletindo o papel do cenário das manifestações culturais.

Concluindo, a dissertação de Nascimento (2015), destaca que os confrontos entre as diferentes facções religiosas, ocorreram, pelo controle das basílicas cristãs, e foi constatado que essas basílicas sustentaram e mantiveram diversos níveis de atrito entre as comunidades religiosas, incentivando as suas concorrências oferecendo durabilidade aos confrontos.

Por fim, em relação ao Programa de Serviço Social, foram levantadas 3 dissertações, que possibilitaram a verificação dos seguintes pontos:

\section{Quadro 4: Dissertações analisadas segundo o Programa de Serviço Social.}

\begin{tabular}{|c|c|c|c|c|}
\hline Titúlo & Autor & Palavras - Chaves & Programa & Universidade \\
\hline $\begin{array}{c}\text { Capuchinhos lombardos no } \\
\text { Maranhão: suas práticas } \\
\text { comunicativas na Cidade de } \\
\text { Imperatriz (1922-1979) }\end{array}$ & $\begin{array}{c}\text { Valdalia Alves } \\
\text { de Andrade }\end{array}$ & $\begin{array}{c}\text { Capuchinhos. Missões } \\
\text { Comunicação. Aspectos } \\
\text { religiosos. Igreja Católica. } \\
\text { Memória coletiva. }\end{array}$ & $\begin{array}{c}\text { Pontifícia } \\
\text { Comunicação e } \\
\text { Semiótica } \\
\text { Universidade } \\
\text { Católica de São } \\
\text { Paulo }\end{array}$ \\
\hline $\begin{array}{c}\text { Os valores religiosos e seus } \\
\text { desdobramentos no cotidiano dos } \\
\text { jovens }\end{array}$ & $\begin{array}{c}\text { Elisa Borri } \\
\text { Vidal }\end{array}$ & $\begin{array}{c}\text { Valores religiosos. } \\
\text { Conservadorismo. } \\
\text { Juventude. }\end{array}$ & Serviço Social & $\begin{array}{c}\text { Pniversidade } \\
\text { Católica de São } \\
\text { Paulo }\end{array}$ \\
\hline $\begin{array}{c}\text { A comunicação da igreja católica no } \\
\text { Brasil: tendências comunicacionais } \\
\text { da Conferência Nacional dos Bispos } \\
\text { do Brasil São Bernardo }\end{array}$ & $\begin{array}{c}\text { Ricardo Costa } \\
\text { Alvarenga }\end{array}$ & $\begin{array}{c}\text { Comunicação Social. Igreja } \\
\text { Católica. Tendências } \\
\text { Comunicacionais. } \\
\text { Bispos do Brasil. } \\
\text { Comunicação e Religião. }\end{array}$ & Comunicação \\
Social & $\begin{array}{c}\text { Univetodista de São } \\
\text { Paulo }\end{array}$ \\
\hline
\end{tabular}


No que diz respeito à dissertação de Vidal (2016), esta tem por objetivo analisar a representatividade destes valores conservadores na vida de jovens vinculados a diferentes religiões, por meio de pesquisas bibliográficas e de campo, de questionários semi estruturados, em pesquisas científicas, possibilitando a compreensão da relação entre conservadorismo, juventude e religião.

A dissertação de Alvarenga (2016), buscou identificar as tendências comunicacionais por contribuir com os estudos relacionados à interface Comunicação e Religião no Brasil. Assim, a pesquisa foi desenvolvida com base em levantamentos bibliográficos, análise documental e entrevistas, que levaram às conclusões de que a CNBB foi influenciada por aspectos sociais, eclesiais, políticos e econômicos.

Concluindo, a dissertação de Andrade (2017), busca entender a articulação da comunicação utilizada pelos missionários italianos para difundir o catolicismo romano. Para a realização desta pesquisa foram utilizadas de fontes sistematizadas em documentos e periódicos ilustrados e fontes orais. Por fim, a pesquisa percorre os desejos de renovação, definidos pelo Concílio Vaticano II.

\section{CONSIDERAÇÕES FINAIS}

A partir do estudo realizado foi possível relacionar através do mapeamento realizado, as várias concepções de territórios religiosos, tendo como base os principais autores que são referência na discussão do tema em âmbito acadêmico. Ainda, por meio do levantamento quanti/qualitativos das produções na plataforma CAPES, foi possível identificar e analisar as principais produções que traziam em seus títulos, resumos ou palavras chaves algum dos descritores pesquisados.

A pesquisa representou um grande desafio para os autores principalmente por se tratar de um tema novo e principalmente por utilizar de novas metodologias de estudo, como foi o caso do levantamento quantitativo e qualitativo das produções. Desta forma, compreende-se que sua importância vai bem além da simples produção apresentada até aqui, mas sim nas infinitas possibilidades de estudo que foram descobertas ao longo de sua elaboração.

Por fim compreende que o processo de construção dos territórios religiosos é um 
processo social que está diretamente associado ao ideário do homem religioso. Diferentemente dos outros processos de ocupação do espaço com óticas econômicas, a visão religiosa não apresenta explicações ligadas ao mundo material, mas sim ao sagrado e as suas várias manifestações.

\section{REFERÊNCIAS}

ALMEIDA, Lorrana Laila Silva de. "DAÍ PRA CÁ É MEU”: Territorialidades no contexto da Festa do Divino Pai Eterno em Trindade-GO. 28/04/2020. Mestrado Geografia do Pontal - PPGEP. Instituição de Ensino: Universidade Federal de Uberlândia, Uberlândia-MG. Disponível em: <https://repositorio.ufu.br/bitstream/123456789/29386/1/DaiPraCaEMeu.pdf>. Acesso em: 13 jul. 2021.

ALVARENGA, Ricardo Costa. A Comunicação da Igreja Católica no Brasil: tendências comunicacionais da Conferência Nacional dos Bispos do Brasil São Bernardo. 22/11/2016 232 f. Mestrado em Comunicação Social. Instituição de Ensino: Universidade Metodista de São Paulo, São Bernardo do Campo. Biblioteca Depositária: UMESP. Disponível em: $<$ https://sucupira.capes.gov.br/sucupira/public/consultas/coleta/trabalhoConclusao/viewTr abalhoConclusao.jsf?popup=true\&id_trabalho=4162973>. Acesso em: 13 jul. 2021.

ANDRADE, Valdalia Alves de. Capuchinhos lombardos no Maranhão: suas práticas comunicativas na Cidade de Imperatriz (1922-1979). 25/05/2017 undefined f. Mestrado em Comunicação e Semiótica. Instituição de Ensino: Pontifícia Universidade Católica de São Paulo, São Paulo. Biblioteca Depositária: PUC/SP. Disponível em: <https://sapientia.pucsp.br/bitstream/handle/20139/2/Vald\%c3\%a1lia\%20Alves\%20de\%20 Andrade.pdf>. Acesso em: 13 jul. 2021.

ARAUJO, Bruno Cesar Cordeiro de. Embates da fé: conflitos religiosos entre congregacionais e católicos no sertão da Paraíba (1930-1940). 30/06/2020 138 f. Mestrado em Ciências da Religião. Instituição de Ensino: Universidade Católica de Pernambuco, Recife. Biblioteca Depositária: Biblioteca Central da UNICAP. Disponível em: <http://tede2.unicap.br:8080/bitstream/tede/1324/5/Ok_bruno_cesar_cordeiro_araujo.pdf >. Acesso em: 13 jul. 2021.

CARMO, Maria Vanessa Nunes do. Mapeamento e Pluralismo: A Territorialidade Religiosa no Bairro do Pina em Recife. 20/03/2017 176 f. Mestrado em Ciências da Religião. Instituição de Ensino: Universidade Católica de Pernambuco, Recife. Biblioteca Depositária: Biblioteca Central da UNICAP (O trabalho não possui divulgação autorizada).

CASTELUBER, Daniel Louzada. A Territorialidade da Igreja Católica em Colatina-ES: Um olhar a partir de Zeny Rosendahl. 09/12/2014 87 f. Mestrado Profissional em Ciências das Religiões Instituição de Ensino: Faculdade Unida de Vitória, Vitória. Biblioteca Depositária: Biblioteca Central Faculdade Unida de Vitória (O trabalho não possui divulgação autorizada). Disponível em: 
<http://bdtd.faculdadeunida.com.br:8080/jspui/bitstream/prefix/147/1/Disserta\%c3\%a7\%c 3\%a3o\%20-\%20Daniel\%20Louzada\%20Casteluber.pdf>. Acesso em: 13 jul. 2021.

CARVALHO, José Rodrigues de. Território da Religiosidade: Fé, Mobilidade e Símbolos na Construção do Espaço Sagrado da Romaria do Senhor do Bonfim em Araguacema, Tocantins. 14/03/2014 156 f. Mestrado em Geografia. Instituição de Ensino: Universidade Federal de Goiás, Goiânia. Biblioteca Depositária: Biblioteca Central da UFG. Disponível em: $<$ https://sucupira.capes.gov.br/sucupira/public/consultas/coleta/trabalhoConclusao/viewTr abalhoConclusao.jsf?popup=true\&id_trabalho=1538349>. Acesso em: 13 jul. 2021.

DIAS, Roberta Cristina Martins. Estratégias de difusão espacial do Protestantismo no Estado do Rio de Janeiro: o caso da Igreja Projeto Vida Nova. 13/09/2016 106 f. Mestrado em Geografia. Instituição de Ensino: Universidade do Estado do Rio de Janeiro, Rio de Janeiro. Biblioteca Depositária: Biblioteca CTC/C Rede Sirius UERJ. Rua São Francisco Xavier 524, 4은 andar, sala 4014, bloco C (O trabalho não possui divulgação autorizada).

FERREIRA, Norma Sandra de Almeida. As pesquisas denominadas "estado da arte". Educ. Soc. [online]. 2002, vol.23, n.79, pp.257-272. Disponível em: <https://www.scielo.br/j/es/a/vPsyhSBW4xJT48FfrdCtgfp/?lang=pt\&format=pdf>. Acesso em: 27 jul. 2021.

FILIPE, Rosana Jardim Madureira. Difusão espacial da religião: Igreja Metodista em São Francisco, Niterói, a prática religiosa em células, (2014). 29/04/2014 129 f. Mestrado em Geografia. Instituição de Ensino: Universidade do Estado do Rio de Janeiro, Rio de Janeiro. Biblioteca Depositária: Biblioteca CTC/C - Rede Sirius, UERJ. Rua São Francisco Xavier 524, 4은 andar, sala 4014, bloco C. (O trabalho não possui divulgação autorizada). Disponível em: <https://www.bdtd.uerj.br:8443/bitstream/1/13339/1/Dissertacao\%20completa.pdf>.

Acesso em: 23 jul. 2021.

HAESBAERT, R. O mito da desterritorialização. Do "fim dos territórios" à multiterritorialidade. Rio de Janeiro:Bertrand Brasil, 2004

MIGUEL, Rogerio Tiago. Religião em Ambientes Digitais: o discurso religioso e possibilidades de diálogo na perspectiva de Mikhail Bakhtin. 22/05/2017 123 f. Mestrado em Ciências da Religião. Instituição de Ensino: Pontifícia Universidade Católica de Minas Gerais, Belo Horizonte. Biblioteca Depositária: Pe. Alberto Antoniazzi. Disponível em: $<$ https://sucupira.capes.gov.br/sucupira/public/consultas/coleta/trabalhoConclusao/view Tr abalhoConclusao.jsf?popup=true\&id_trabalho=5068456>. Acesso em: 13 jul. 2021.

MOURA, Marcos Roberto Pereira. A romaria de Santa Luzia: contribuições da fé para a construção de uma identidade territorial na comunidade de Santa Luzia - município de Porangatu/GO. 17/11/2015 206 f. Mestrado em Geografia. Instituição de Ensino: Universidade Federal de Goiás, Goiânia. Biblioteca Depositária: Biblioteca Central da UFG. Disponível em: <https://sucupira.capes.gov.br/sucupira/public/consultas/coleta/trabalhoConclusao/viewTr abalhoConclusao.jsf?popup=true\&id_trabalho=3452159>. Acesso em: 13 jul. 2021. 
MORAIS, Juliana Marques. Levantes Religiosos e Combate ao Diabo: Concepções e Práticas Sociais no Norte da África entre os séculos IV e V. 28/08/2014 104 f. Mestrado em História Social. Instituição de Ensino: Universidade Estadual de Londrina, Londrina. Biblioteca Depositária: Biblioteca Central da Universidade Estadual de Londrina (UEL). Disponível em: $<$ https://sucupira.capes.gov.br/sucupira/public/consultas/coleta/trabalhoConclusao/viewTr abalhoConclusao.jsf?popup=true\&id_trabalho=2090150>. Acesso em: 13 jul. 2021.

MOTA, Aline Ellen dos Santos. Católicos: "Falsos" Versus "Verdadeiros": Observando relações de poder entre dois grupos religiosos na cidade de Capanema-PA. 14/10/2016 151 f. Mestrado em Ciências da Religião. Instituição de Ensino: Universidade do Estado do Pará, Belém Biblioteca Depositária: Biblioteca Paulo Freire - Centro de Ciências Sociais e Educação da UEPA (O trabalho não possui divulgação autorizada).

NASCIMENTO, Giovan do. As relações entre os confrontos religiosos e os lugares cristãos das cidades do Norte da África durante a Antiguidade Tardia (Séculos IV - VI D.C.). 07/07/2015 95 f. Mestrado em História Social. Instituição de Ensino: Universidade Estadual de Londrina, Londrina. Biblioteca Depositária: BC-UEL. Disponível em: $<$ https://sucupira.capes.gov.br/sucupira/public/consultas/coleta/trabalhoConclusao/viewTr abalhoConclusao.jsf?popup=true\&id_trabalho=3106906>. Acesso em: 13 jul. 2021.

RAFFESTIN, Claude. O que é o Território? In: Por uma geografia do poder. São Paulo: Ática, 1993. p. 144-220.

REIS, Suellen Santiago dos. De lugar segregado ao lugar espiritual da Teologia da Libertação: Diocese de Nova Iguaçu de 1970 a 1990. 07/02/2013 135 f. Mestrado em Geografia. Instituição de Ensino: Universidade do Estado do Rio de Janeiro, Rio de Janeiro Biblioteca Depositária: CTC/C (O trabalho não possui divulgação autorizada). Disponível em: <https://www.bdtd.uerj.br:8443/bitstream/1/13342/1/Dissertacao\%20completa.pdf>.

Acesso em: 13 jul. 2021.

ROSENDAHL, Z. (Orgs.) Geografia Cultural: um século (3). Rio de Janeiro: EdUERJ, 2002.

SAMPAIO, Debora Vanessa Regis Ferreira. Campina Grande (PB). A "Capital da Fé": entre Territórios e (re)Construções Identitárias. 09/08/2018 165 f. Mestrado em Geografia Instituição de Ensino: Universidade Estadual do Oeste do Paraná, Marechal Cândido Rondon. Biblioteca Depositária: Unioeste - Campus de Marechal Cândido Rondon. Disponível em: $<$ https://sucupira.capes.gov.br/sucupira/public/consultas/coleta/trabalhoConclusao/viewTr abalhoConclusao.jsf?popup=true\&id_trabalho=6592402>. Acesso em: 13 jul. 2021.

SANTOS, M. O espaço: sistema de objetos, sistemas de ação. In: A natureza do espaço: técnicas e tempo - razão e emoção. 2.ed. São Paulo: Hucitec, 1997.

SHIOTA, Hanae Caroline Quintana; DORSA Arlinda Cantero.O estado da arte e as técnicas de análise de conteúdo segundo Laurence Bardin. In: As Interfaces da Diversidade, do Patrimônio e da Globalização a partir das Produções Científicas. Org. Arlinda Cantero Dorsa e Antonio Henrique M. Lima. - Campo Grande, MS: Life Editora, 2021 
SILVA, Eliete Furtado Cecilio e. Campo da Fé: Território e Territorialidades dos peregrinos sergipanos na Jornada Mundial da Juventude: Rio de Janeiro/2013. 22/06/2016 204 f. Mestrado em Geografia. Instituição de Ensino: Fundação Universidade Federal de Sergipe, São Cristóvão Biblioteca Depositária: undefined. Disponível em: <https://ri.ufs.br/handle/riufs/5517>. Acesso em: 13 jul. 2021.

SILVA, Silbene Correa Perassolo da. A Festa de São Benedito: Estudo sobre a invenção de uma tradição cuiabana. 30/05/2014 238 f. Mestrado em História. Instituição de Ensino: Universidade Federal de Mato Grosso, Cuiabá. Biblioteca Depositária: Biblioteca Central da Universidade Federal de Mato Grosso. Disponível em: $<$ https://sucupira.capes.gov.br/sucupira/public/consultas/coleta/trabalhoConclusao/viewTr abalhoConclusao.jsf?popup=true\&id_trabalho=1695250>. Acesso em: 13 jul. 2021.

SLONGO, lône Inês Pinsson. A produção acadêmica em ensino de biologia: um estudo a partir de teses e dissertações. Florianópolis : UFSC, 2004. Disponível em: $<$ https://repositorio.ufsc.br/xmlui/bitstream/handle/123456789/88012/205538.pdf?sequen ce=1\&isAllowed=y>. Acesso em: 27 jul. 2021.

VIDAL, Elisa Borri. Os Valores Religiosos e seus Desdobramentos no Cotidiano dos Jovens. 11/03/2016 106 f. Mestrado em Serviço Social. Instituição de Ensino: Pontifícia Universidade Católica de São Paulo, São Paulo Biblioteca Depositaria: PUCSP. Disponível em: $<$ https://sucupira.capes.gov.br/sucupira/public/consultas/coleta/trabalhoConclusao/viewTr abalhoConclusao.jsf?popup=true\&id_trabalho=3690798>. Acesso em: 13 jul. 2021. 